\title{
Selection and characterization of potential probiotic bacteria for Litopenaeus stylirostris shrimp hatcheries in New Caledonia
}

\author{
Dominique Pham ${ }^{\mathrm{a}, *}$, Dominique Ansquer ${ }^{\mathrm{a}}$, Anne Chevalier ${ }^{\mathrm{a}}$, Clément Dauga ${ }^{\mathrm{a}}$, Aude Peyramale $^{\mathrm{a}}$, \\ Nelly Wabete ${ }^{a}$, Yannick Labreuche ${ }^{b, c, d}$
}

\footnotetext{
a Département Lagons, Ecosystèmes et Aquaculture Durables en Nouvelle-Calédonie, IFREMER, BP 2059, 98846 Nouméa cedex, New Caledonia

b Département Physiologie Fonctionnelle des Organismes Marins, IFREMER, Centre Bretagne Z.I. Pointe du Diable, F-29280 Plouzané, France

c Sorbonne Universités, UPMC Université Paris 06, UMR 8227, Integrative Biology of Marine Models, Station Biologique de Roscoff, CS 90074, F-29688, Roscoff cedex, France

d CNRS, UMR 8227, Integrative Biology of Marine Models, Station Biologique de Roscoff, CS 90074, F-29688, Roscoff cedex, France
}

*: Corresponding author : Dominique Pham, tel.: + 687352583 ; fax: + 687351177 ; email address : dominique.pham@ifremer.fr

\begin{abstract}
:
In New Caledonia, shrimp hatcheries are confronted with mass mortality in the larval stages, a phenomenon poorly understood as no specific causative agent has been identified. This has resulted in an excessive use of prophylactic antibiotics, although their adverse effects in aquaculture are notorious. The present work was thus aimed at selecting potential probiotic strains for penaeid hatcheries.
\end{abstract}

From a pool of more than 400 marine bacterial isolates sampled from the local marine environment seven strains exhibited in vitro antagonistic activity towards Vibrio harveyi. These isolates were characterized both phenotypically and genotypically using a biochemical approach and 16S rDNA sequencing. Six out of these seven strains were found to belong to the genus Pseudoalteromonas, the last one belonging to the Vibrionaceae family and related to the Harveyi clade. Selected probiotic candidates were individually tested for antagonistic activities in vitro using a green fluorescent protein (GFP)-labelled transconjugant of $V$. harveyi and for inherent pathogenicity towards cultured shrimp larvae at two different developmental stages. This approach enabled rapid processing and selection of candidates to be tested in our experimental hatchery. Four different experiments were conducted to test candidate strains either alone or in combination. Repeated trials showed that postlarval survival was significantly improved by adding the strain NC201 individually to the rearing water compared to unchallenged controls. The analysis of immune-related gene expressions showed that the Litsty PEN3 transcript abundance of larvae was significantly increased after being reared in probiotic-containing water; however no significant difference in lysozyme gene expression was recorded in this study. Together, these results open new insights into the use of these strains as potential substitutes to antibiotherapy in shrimp larval rearing in New Caledonia. 


\section{Highlights}

Seven bacterial isolates belonging to Pseudoalteromonas and Vibrionaceae. Antagonistic activities of the isolates against $V$. harveyi - Postlarval survival improved by adding a Pseudoalteromonas strain in water. Litsty PEN3 transcript abundance of larvae increased by using probiotic.

Keywords : shrimp ; Litopenaeus stylirostris; Probiotic ; Hatchery ; Pseudoalteromonas ; Vibrio ; immune response 


\section{Introduction}

In New Caledonia (South Pacific) the shrimp culture industry represents the second largest export industry with an annual production of 2200 metric tons and 167 million postlarvae in 2005 (Etablissement de Régulation des Prix Agricoles, ERPA, 2008) and is based upon the Pacific blue shrimp Litopenaeus stylirostris. However, this production has dramatically dropped to 1200 metric tons and 123 million juveniles per year since 2009. In grow-out ponds this decline is mainly due to two seasonal vibrioses responsible for recurring mortality outbreaks. The first, named 'Syndrome 93', mainly occurs during the southern winter (from mid-May to mid-September) and is caused by Vibrio penaeicida (Goarant et al., 1999). The second vibriosis, due to V. nigripulchritudo, occurs during the warm season (from midNovember to mid-April) and is called 'Summer Syndrome' (Goarant et al., 2006; Le Roux et al., 2011; Goudenège et al., 2013). Mass mortality of larval stages have also been increasingly observed in New Caledonian hatcheries but this phenomenum remains poorly understood as no specific causative agent has yet been identified although bacterial infection is frequently suspected. The growing demand for juveniles to stock grow-out ponds has led local hatcheries to increase shrimp stocking densities and/or production cycle numbers. This phenomenon has been accompanied by the increased input of prophylactic antibiotics to prevent the occurrence of bacterial diseases. Unfortunately, this approach is doomed to failure since it contributes to the development of antibiotic-resistant pathogens and also to the dissemination of resistance determinants between aquatic and anthropogenic sources (Cabello, 2006; Thuy et al. 2011). The role of probiotic agents is therefore increasingly being investigated in aquatic animal rearings as an alternative to antibiotic treatments (Gomez-Gil et al., 2000; Lakshmi et al.,2013). 
The use of probiotics for an aquatic usage started with candidates derived from agricultural sources, such as lactic acid bacteria (LAB) and yeasts, or with selected bacteria from the gastrointestinal tract of aquatic animals (Kesarcodi-Watson et al., 2008). Nowadays numerous microorganisms, including these isolated from marine environments, are used as probiotics. Although the definition still differs depending on the author, there now exists a certain consensus as to which aquatic probiotic microorganisms are beneficial to the host through several modes of action including, but not restricted to: growth promotion, inhibition of pathogens, improvement in nutrient digestion and/or of water quality, increase of stress tolerance and effects on reproduction.

In the shrimp industry probiotics have mainly been tested in juveniles or adults. The literature on probiotics in shrimp hatcheries remains scarce (reviewed in Gomez-Gil et al., 2000). In New Caledonia L. stylirostris juveniles were fed over a one month period with a diet containing the probiotic Pediococcus acidilactici. This was shown to enhance antioxidant defences and oxidative stress status and also to reduce shrimp mortality in the probiotic group during an experimental challenge with V. nigripulchritudo (Castex et al., 2010). By comparison with the information acquired for juveniles and adults few results are available regarding the use of probiotics in L. stylirostris larval stages. Several commercial preparations have been tested in the last few years at the IFREMER experimental hatchery in New Caledonia but the results were not reproducible. This present study was therefore aimed at 1) identifying candidate bacteria from the New Caledonian marine environment with probiotic abilities and at 2) evaluating their effects on survival, growth and host immune response during shrimp larval rearing. 


\section{Material and methods}

\subsection{Bacterial isolates}

Seven bacterial strains designated NC72, NC197, NC201, NC203, NC204, NC257 and NC297 were selected from a collection of 493 marine bacterial isolates sampled during a bioprospection in marine intertidal areas of New Caledonia (Chalkiadakis et al., 2013). These strains were selected for growth inhibition activity against $V$. nigripulchritudo, a shrimp pathogen in New Caledonia, in a diffusion agar assay (Dupont-Rouzeyrol M., pers.com.). The green fluorescent protein (GFP)-expressing $V$. harveyi strain (ORM4-GFP) has been previously described (Travers et al., 2008). Briefly, the pVSV102 plasmid (Dunn et al., 2006) harboring GFP and kanamycin-resistance expression cassettes was transferred from E. coli to $V$. harveyi ORM4 by triparental mating using the conjugative helper strain CC118 $\lambda$ pir as described by Dunn et al. (2006). Bacterial isolates were grown in marine broth (MB) or marine agar (MA) at $28^{\circ} \mathrm{C}$. Kanamycin $(50 \mu \mathrm{g} / \mathrm{ml})$ was added as supplement for cultivation of the ORM4-GFP on MA plates. Pure cultures of each strain were cryopreserved at $-80^{\circ} \mathrm{C}$ using MB media supplemented with $10 \%$ glycerol.

\subsection{Identification of bacterial strains}

Phenotypic and molecular identification analyses were performed to identify the seven candidate strains. After Gram-staining and morphological characterization the isolates were subjected to phenotypic tests for conventional identification using the API 20E commercial kit (Api System; BioMérieux, Marcy l’Etoile, France).

Extraction and amplification of bacterial template DNA for 16S rRNA sequence analysis were carried out as described previously (Labreuche et al., 2012; Walling et al., 2010). The DNA sequences were compared against the sequences available in the databases obtained 
from the National Center for Biotechnology Information using the BLAST algorithm (http://www.ncbi.nlm.nih.gov/BLAST/) to determine nucleotide-nucleotide similarity with sequences in the nr/nt database. The $16 \mathrm{~S}$ rRNA gene sequences determined in this study have been deposited in GenBank under accession nos KJ557107, KJ557108, KJ557109, KJ557110, KJ557111, KJ557112 and KJ557113.

\subsection{Co-culture tests}

The relationship between fluorescence and CFU.mL ${ }^{-1}$ of $V$. harveyi ORM4-GFP monocultures was tested previously. Results indicated that the fluorescence signal generated by the GFP-expressing cells could be used to indirectly quantify the bacterial growth during $48 \mathrm{~h}$ co-culture with probiotic candidates (data not shown).

To evaluate the activity of probiotic candidates, MB was inoculated with PBS suspensions of V. harveyi ORM4-GFP (initial concentration $1 \times 10^{5}$ CFU.mL ${ }^{-1}$ ) separately or in combination with PBS suspensions of candidate probiotics (final concentration $1 \times 10^{5} \mathrm{CFU} \cdot \mathrm{mL}^{-1}$ ) in sterile culture tubes (final volume $10 \mathrm{~mL}$ ). All treatments were performed in triplicate. Tubes were incubated for $48 \mathrm{~h}\left(28^{\circ} \mathrm{C}, 190 \mathrm{rpm}\right)$. Growth of the GFP-tagged V. harveyi cells was monitored indirectly by measuring fluorescence (excitation/emission 485/520 nm) with a SYNERGY absorbance microplaque reader (Biotek) and data were collected with the GEN5 ${ }^{\mathrm{TM}}$ software (Biotek). Fluorescence values were adjusted by subtracting the average autofluorescence generated from corresponding controls.

The antagonistic activity of each strain was classified based on their ability to reduce the $V$. harveyi ORM4-GFP fluorescence signal after $48 \mathrm{~h}$ relative to the maximum signal reduction recorded for the respective assay. In this way, strain antagonistic activity was classified as low ( $<50 \%$ of $\max )$, moderate $(50-75 \%$ of $\max )$, or strong $(>75 \%$ of $\max )$. 
2.4 Effects of probiotic candidates on larval survival

Selected probiotic candidates were individually tested for inherent pathogenicity towards cultured shrimp larvae at two different developmental stages (Mysis 2 and PL9 stages). Twenty-four hours before probiotic inoculation, Mysis 2 larvae were collected from the larval rearing tanks, rinsed with sterile seawater and transferred into $500 \mathrm{~mL}$ beakers containing filtered aerated seawater at $29^{\circ} \mathrm{C}$ for a concentration of 10 larvae. $\mathrm{mL}^{-1}$. Mysis 2 larvae were fed three times a day with 50-100 $\mu \mathrm{m}$ feed particles. Each beaker was inoculated once with an individual probiotic candidate at a final concentration of $1 \times 10^{5} \mathrm{CFU} \cdot \mathrm{mL}^{-1}$ or sterile culture medium as a control and incubated at $29^{\circ} \mathrm{C}$. Each probiotic candidate was tested in duplicate. Survival was monitored for $48 \mathrm{~h}$.

PL9 larvae were stocked in $30 \mathrm{~L}$ aquaria containing filtered aerated seawater at ambient temperature $\left(27-28^{\circ} \mathrm{C}\right)$ for a concentration of 1 larva. $\mathrm{L}^{-1}$. Animals were fed with $500-800 \mu \mathrm{m}$ pellets. Each aquarium was inoculated once with an individual probiotic candidate at a final concentration of $1 \times 10^{5}$ CFU.mL $\mathrm{mL}^{-1}$ or sterile culture medium as a control and incubated at ambient temperature. Each probiotic candidate was tested in triplicate. Survival was monitored for $72 \mathrm{~h}$.

2.5 Protective effect of candidates during larval and postlarval rearing experiments

2.5.1. Animals and larval rearing management

Four different larval experiments were conducted at the IFREMER experimental hatchery of Saint-Vincent (Boulouparis, New Caledonia) between May 2011 and July 2013. L. stylirostris nauplii (Nii) were obtained from captive broodstock reared according a previously described protocol (Pham et al., 2012) and were collected from the same hatching tank for each trial. In the first three experiments larvae were reared in 100-L tanks while in the last one tests were conducted in 1.5 cubic meter tanks. Initial stocking density was between 160 to 180 nauplii 
per litre of seawater with salinity between 33-35 ppt. The water temperature was maintained at $30-31{ }^{\circ} \mathrm{C}$ and a $14 \mathrm{~h}: 10 \mathrm{~h}$ day:night photoperiod was used. Microparticles $(5-50 \mu \mathrm{m}$, Bernaqua) were distributed 30 hours after stocking larvae and live preys (Artemia spp.) from day 5; larvae were fed ad libitum. At zoea 3, postlarvae 1 and postlarvae 3 stages, microparticle sizes were increased to $50-100,100-200$ and $200-300 \mu \mathrm{m}$ respectively. Temperature, salinity, survival and growth were measured daily. The first experiment ended at day 9. The three others lasted between 18 and 20 days. Fifty percent of water was renewed at day 9, day 11, day 13 and so forth.

\subsubsection{Treatments}

In the first 3 experiments all the treatments were done in triplicate. Two treatments were used as controls. The first one (designated negative control, NT) received no antibiotics nor selected candidates. The second one (designated antibiotic treatment, $\mathrm{AB}$ ) corresponded to the prophylactic treatment routinely applied in the hatchery (administration of erythomicyn at $2 \mathrm{ppm}$ at days $3,5,7$ and 9).

In the first trial five of the seven selected candidates (NC72, NC197, NC201, NC203 and NC297) were added daily to the tank water at a final concentration of $10^{5} \mathrm{CFU} \cdot \mathrm{mL}^{-1}$. The experiment was ended at day 9. In the second experiment, one of the most promising candidates was tested using an alternative administration protocol which differed from the first trial by enriching larvae with the probiotic candidate for a longer time (from day 0 to day 18) either every day (NC201) or every second day $\left(\mathrm{NC} 201^{1 / 2}\right)$. The third experiment was also conducted during a complete larval rearing. During this trial larvae were enriched every second day with two probiotic candidates (NC201 and NC203) either separately or in combination (at a final concentration of $10^{5} \mathrm{CFU} \cdot \mathrm{mL}^{-1}$ ). The first administration of selected candidates started the day before stocking nauplii in the rearing tanks. Finally a last 
experiment was conducted under pilot scale conditions in 1.5 cubic meter tanks during a complete larval rearing (20 days). Nauplii from the same hatching tank were divided into 2 tanks (180 nauplii/l). In one tank NC201 was administrated to the water one day before stocking larvae and then every second day at a final concentration of $10^{5} \mathrm{CFU} \cdot \mathrm{mL}^{-1}$. In the second tank animals did not receive any treatment and were considered as controls. This experiment was done three times.

\subsubsection{Growth and Survival}

In each experiment survival was estimated daily by counting the number of larvae in a 100$\mathrm{mL}$ volume in three to five replicates. From Nii to PL1 the larvae were sampled to determine the effect of the potential probiotics on larval development and rate of development, using a development index (DI) described by Villegas and Kanazawa (1980): DI $=(\Sigma[\mathrm{i}$ ni $]) / \mathrm{n}$, where $\mathrm{i}$ is the absolute value attributed to each larval stage (Nii=0, Zoea $1=1$, Zoea $2=2, \ldots$ and $7=$ PL1), ni is the total number of larvae at stage $\mathrm{I}$, and $\mathrm{n}$ is the number of organisms measured. From PL1 growth was estimated by individual mean dry weight (MDW) in 100 individuals for each replicate.

2.5.4 Quantitative PCR (qPCR) analysis of antimicrobial peptide gene expression Expression profiles of genes coding for the antimicrobial peptides (AMPs) Litsty PEN3 and lysozyme (GenBank accession numbers AY351655 and CV699332, respectively) were analyzed by qPCR to examine the general pattern of expression during the course of probiotic candidate administration. During the third in vivo experiment 20 animals were sampled from each tank at day 9 (around metamorphosis) and 10 animals at day 19 (at the end of the larval rearing). Total RNA was extracted using RNeasy columns (Qiagen) according to the manufacturer's instructions. RNA quantity, purity and integrity were verified 
spectrophotometrically $\left(A_{260} / A_{280}\right)$ and by electrophoresis on $1 \%$ agarose gels. Quantitative PCR was performed on an ABI 7300 system as previously described (Labreuche et al., 2009). Amplification efficiencies for all qPCR primers were determined according to Pfaffl (2001) and the specificity of the PCR amplification verified from the melting curve. Each run included the cDNA control, negative controls (total RNA treated with DNase I), and blank controls (water). The relative mRNA expression levels were determined using the two standard curves methodology (QuantiTect® SYBR Green PCR Handbook). The elongation factor 1- $\alpha$ gene (EF1, accession no. AY117542.1) was used as the internal reference (normaliser) mRNA. Real-time PCR primer sequences were previously published (de Lorgeril et al., 2008).

\subsection{Statistical analysis}

All numerical data were expressed as the mean \pm standard error. Significant differences between treatments during each assay were tested by one-way analysis of variance (ANOVA) or the Kruskal-Wallis test in case of heterogeneity of variances. Data collected as percentages were transformed (arcsin of the square root) before analysis but are presented in figures as untransformed percentage values. Statistical analyses were performed with XLSTAT2011 software. 


\section{Results}

\subsection{Strain characterization}

All the tested strains were Gram-negative, rod-shaped cells and motile. Only the strain NC72 was able to grow on TCBS agar. NC72 formed swarming white colonies on MA, while the other candidates were orange circular colonies. Table 1 shows the results of the identification of the seven selected isolates with the API 20E system. PCR amplified a fragment of the expected size (1500 bp) from the $16 \mathrm{~S}$ rRNA gene for the seven tested strains. Gene sequence analysis using the maximum-likelihood method indicated that strain NC72 belongs to the genus Vibrio and is included in the Harveyi clade (Fig. 1) (Sawabe et al., 2007). Phylogenetic analysis revealed also that the six other selected strains are closely related to type strains of the genus Pseudoalteromonas (Fig. 1).

\subsection{Co-culture tests}

Probiotic candidates were co-cultured with $V$. harveyi ORM4-GFP at equal starting concentrations $\left(1 \times 10^{5}\right.$ CFU. $\left.\mathrm{mL}^{-1}\right)$ to evaluate their antagonistic activities (Fig. 2). Strain NC257 had no significant effect on V. harveyi ORM4-GFP growth (P>0.05). The Vibrio strain NC72 caused a strong inhibition (> 93\%), which resulted in an almost total elimination of the fluorescent signal. Candidates belonging to the Pseudoalteromonas genus demonstrated an antagonistic activity that could also be classified as strong (> 75\%), except for the strain NC297 which displayed a moderate effect on $V$. harveyi ORM4-GFP growth (72,5\%).

\subsection{Effects of probiotic candidates on larval survival}

An initial in vivo experiment was performed to determine whether the selected probiotic candidates themselves showed harmful effects on larval survival. As indicated in Fig. 3, 
exposure of Mysis 2 or PL9 shrimp larvae to a single dose of $1 \times 10^{5} \mathrm{CFU} \cdot \mathrm{mL}^{-1}$ of the probiotic candidates did not alter animal survival relative to the unchallenged control (Kruskal-Wallis, P>0.05).

\subsection{Protective effect of selected candidates during larval and postlarval rearing}

Representatives were short listed based on the strength of their in vitro antagonism towards $V$. harveyi to select strains capable of protective effects on shrimp larvae. Preference was given towards isolates belonging to the Pseudoalteromonas genus. In this way the pool of probiotic candidates was reduced to five isolates for further in vivo evaluation.

In the first assay the five probiotic candidates were used individually in larval rearing for nine days. Results indicated that percent survival of shrimp larvae treated with the strain NC297 was significantly higher $(\mathrm{P}<0,05)$ than in the control group (NT treatment) at the end of the experiment (Fig. 4). Treatment with the other probiotic candidates enhanced survival slightly, but not significantly, relative to the NT and AB controls. Regarding the zootechnical parameters, the best larvae DI were obtained in NC201, NC203 and NC297 treatments, DI values ranging between 6.6 and 6.8. The $\mathrm{AB}$ treatment generated the statistically lowest $\mathrm{DI}$ value (5.9) compared to all other treatments $(\mathrm{P}<0,05)$.

In a second experiment only the probiotic candidate NC201 was tested. After 9 days shrimp survival in $\mathrm{AB}$ treatment (86\%) differed significantly from that of the NT treatment $(58.8 \%)$ (Fig. 5). NC201 and NC201 ${ }^{1 / 2}$ treatments (survival rate of $74.9 \%$ and $70.7 \%$, respectively) did not significantly improved shrimp larvae survival compared to the AB and NT treatments. At the end of the experiment larvae receiving no antibiotics nor selected candidates (NT treatment) had the lowest survival (35.2\%), this difference being significant compared to the $\mathrm{AB}, \mathrm{NC} 201^{1 / 2}$ and $\mathrm{NC} 201$ treatments $(\mathrm{P}<0,05)$. No significant differences in individual mean dry weight (MDW) were observed between the different treatments. 
Administration of probiotic candidates NC201 and NC203 either singularly or in combination every second day did not significantly improve larvae survival at day 9 (Fig. 6); however, the $\mathrm{NC} 201^{1 / 2}$ treatment significantly enhanced shrimp survival at the end of the larval rearing. $\mathrm{AB}, \mathrm{NC} 203^{1 / 2}$ and $\mathrm{NC} 201+\mathrm{NC} 203^{1 / 2}$ treatments slightly increased survival compared to the NT treatment, but the difference was not significant $(\mathrm{P}>0,05)$. The highest individual MDW were observed in larvae administrated with the probiotic candidates (singularly or in combination); however, these values were not significantly different from that of the $\mathrm{AB}$ and NT treatments.

In the last experiment under pilot scale conditions, larval survival did not significantly differ at day 9 between the NT treatment $(78 \pm 3.6 \%)$ and the NC201-treated shrimp $(69.8 \pm 15 \%)$. At the end of the larval rearing the average survival rate was enhanced 1.7 fold for NC201 relative to the NT treatment although this difference was not significant $(\mathrm{P}>0.05)$. Mean values of final individual dry weights at day 19 were quite similar between the two treatments (0.223 $\pm 0.45 \mathrm{mg}$ for NC201 and $0.222 \pm 0.39 \mathrm{mg}$ for the NT treatment).

\subsection{AMP gene relative expression}

Experiments were conducted to explore the effects of the candidate probiotic strains NC201 and NC203, administrated either singularly or in combination, on the expression profiles of two genes coding for the AMPs Litsty PEN3 and lysozyme during larval rearing. As indicated in Fig. 7A, lysozyme transcript abundance varied from 1.47 (control) to 1.88 (NC201) at day 9 but the differences were not significant between the different tested treatments (ANOVA, P>0.05). Similarly, no significant difference in lysozyme expression pattern was observed at the end of the larval rearing (day 19) between the different treatments. For penaeidin family, Litsty PEN3 mRNA levels increased significantly at day 9 by 2 to 3 fold in 
larvae administrated with the probiotic candidates NC203 and NC201+NC203 respectively (Fig. 7B), compared to the other treatments $(\mathrm{P}<0.05)$. At the end of the larval rearing (day 19), Litsty PEN3 mRNA transcript abundance did not vary significantly between the different treatments. 


\section{Discussion}

In this work we found that six out of the seven isolates initially selected for their growthinhibitory activity against $V$. nigripulchritudo were related to the Pseudoalteromonas genus, only one isolate belonged to the Vibrio genus. Vibrio and Pseudoalteromonas are some wellknown proteobacterial genera frequently observed in marine environments (Gauthier et al., 1995; Thompson et al., 2004). One interesting feature of the Pseudoalteromonas genus is that it can be divided into two clades: pigmented and nonpigmented species. The pigmented species tend to produce bioactive compounds with antibacterial, antifouling and antibiofilm activities while the non pigmented species generally have broader environmental tolerance than the pigmented ones (Bowman, 2007). Interestingly, our six Pseudoalteromonas isolates were colored strains, forming orange colonies.

We subsequently evaluated bacterial ability to out-compete a target organism in vitro. Antagonism is considered an important attribute of aquaculture probionts and is thus widely used as a selection criterion to select potential probiotic bacteria. Typically, antagonistic activities are evaluated using well diffusion assays. However, several works have shown that particle-attached bacteria are more likely to produce inhibitory compounds than their freeliving counterparts (Long \& Azam, 2001). Since we planned to add the probiotic organisms to the culture water in the tanks (i.e. as free-living cells) we assessed the activity of candidate probiotics with suspensions of a GFP-labelled $V$. harveyi strain. Using this system, we showed that the planktonic forms of all tested strains inhibited V. harveyi ORM4-GFP growth. The strain NC297 displayed only a moderate inhibitory effect compared to the other Pseudoalteromonas strains despite showing similar antagonistic activity in well diffusion assays which supports previous observations (Dheilly et al., 2010). It is not known which antagonistic mechanisms are used by the candidate strains tested in the current study. 
One of the most important features of a probiotic is that it must not be pathogenic or toxic to its host (Kesarcodi-Watson et al., 2008). This was determined by small-scale challenge tests of shrimp larvae using direct addition of the bacterial suspension to the culture water. We performed these tests at two different developmental stages (Mysis 2 and PL9). Previous studies have reported variations in susceptibility of shrimp to infection by Vibrio $\mathrm{sp}$ at different stages (Goarant et al., 1998; Aguirre-Guzmán et al., 2001). We did not observe for the two developmental stages any modification of animal survival following administration of the six Pseudoaltermonas strains or the Vibrio strain NC72. This is in accordance with another study showing that the Pseudoalteromonas strain S2V2 did not cause any mortality in L. vannamei shrimp postlarvae even at $10^{7}$ cells. $\mathrm{ml}^{-1}$ (Isnansetyo et al., 2009). In spite of these results, we decided to rule out the Vibrio strain $\mathrm{NC72}$ as a candidate for further development. Indeed, Vibrio is a genus of highly adaptable bacteria (Thompson et al., 2004). This adaptability is partly driven by lateral gene transfer (LGT), a process known to significantly contribute to the evolution and dissemination of virulence determinants in Vibrio genomes (Wozniak \& Waldor, 2010). Although several species of Vibrio have been reported as potential probiotics in cultured invertebrates (Gomez-Gil et al., 2000 ;Thompson et al., 2010) we considered that there exists a risk in the selection of Vibrio as probiotics, especially regarding the strain NC72 which is closely related to the Harveyi clade (that comprised known marine invertebrate pathogens).

We next investigated the potential probionts during different larval rearing period lengths using 100-L rearing tanks. Initially, the four Pseudoalteromonas strains were used individually in larval rearing for nine days but only one candidate strain could significantly enhance shrimp survival. We consequently modified the administration strategy so that the strains were supplied during a complete larval rearing. In these conditions we showed a significantly enhanced survival in animals administrated with the strain NC201 in the second 
part of the rearing period, between day 10 to day 19. The effectiveness of candidate probiotics is thus closely related to the duration of exposure, as previously reported (Verschuere et al., 2000 ; Nimrat et al., 2011). In shrimp and other crustaceans probiotic candidates are mostly investigated separately and their use in combination remains poorly investigated. Their individual advantages might be additive or even synergistic but this hypothesis had to be qualified. Our results show that administration of NC201 and NC203 in combination did not significantly enhance shrimp survival when compared with the administration of NC201 individually. More research is needed with a variety of multi-strain preparations to clarify which probiotics within a mixture may exhibit a synergistic relationship that might enhance the preparation effectiveness.

In the last experiment we investigated under pilot scale conditions the effects of the strain NC201 administrated every second day. Survival rates of shrimp receiving the probiotic candidate were repeatedly higher than that of control animals with an average survival rate enhanced by 1.7 fold at the end of the larval rearing period; however, this difference was not statistically significant. Although we adopted strict management practices and optimized the conditions for parameters such as feed rates, water dissolved oxygen, salinity, stocking densities and water temperature, there is always substantial variation in the water quality as well as in the microbial environment that may explain the observed variability among the results of our three experiments in large-scale conditions. These data demonstrate that the development of suitable probiotics is not a simple task and point out the need to perform fullscale trials.

The beneficial effects of probiotic administration have been suggested as sources of nutritional and enzymatic distribution for digestion (Verschuere et al., 2000). Nevertheless we did not observe any significant effect of the candidates on final individual dry weights throughout our experiments. To gain a better understanding of the modes of action of these 
candidates, we performed screening experiments for stimulation of the immune response system. The effects of probiotics on shrimp defense mechanisms at the molecular level have been poorly investigated so far. In L. vannamei, administration of Lactobacillus plantarum in the diet induced up-regulation of prophenoloxidase (proPO) and peroxinectin (PE) mRNA transcription levels and enhancement of cellular and humoral immune responses, such as PO activity, SOD activity, and clearance efficiency against V. alginolyticus (Chiu et al., 2007). More recently, a study reported that the mRNA levels of proPO, PE, lipopolysaccharide- and $\beta$-1,3-glucan-binding protein and serine protein were significantly up-regulated in L. vannamei shrimp administrated with a mixture of two B. subtilis probiotic strains (Zokaeifar et al., 2012). In the present work we have focused on two effectors of the immune response, penaeidin Litsty PEN3 and lysozyme. This choice is based on previous results which demonstrated that these two genes present striking predictive interest regarding the potential capacity of L. stylirostris shrimp to survive a Vibrio infection (de Lorgeril et al., 2008). In our study lysozyme did not show differences in transcript abundance between the control group and shrimp administrated with NC201 and NC203 either individually or in combination. Instead Litsty PEN3 mRNA levels increased significantly at day 9 by two to three fold in larvae administrated with NC203 and NC201+NC203 respectively. Results from several reports show the diverse responses in mRNA expression of lysozyme to different immunostimulants (Wang et al., 2008; Maeda et al., 2013). This may be the result of the different mechanisms they employ in regulating the mRNA expression of this AMP. As penaeidins play an important role in shrimp defense (Destoumieux et al., 2000), the transcriptional activation of Litsty PEN3 following administration of the candidate probiotics represents a possible indicator of the immune state of shrimp. Whether NC203 and NC201+NC203-stimulated shrimp are more able to eliminate pathogenic bacteria than naive animals needs to be determined. The ability of probionts to improve resistance against 
infections has been frequently tested by challenging the host species in vivo through the addition of a representative pathogen (Verschuere et al., 2000). However, mortality events of shrimp larvae in New Caledonia has not yet been attributed to any specific causative agent. In addition, in vivo experiments can not test all possible pathogens, making it difficult to draw conclusions about the tested pathogens when they may not occur as part of the normal or natural larval system microflora. Therefore, we considered that in vivo challenge experiments were not relevant for the selection of probiotics for New Caledonian hatcheries.

\section{Conclusion}

This study allowed us to show that alternative approaches to the use of antibiotics can be implemented in New Caledonia to promote reliable hatchery productions and that the strain NC201 could be a good possible probiotic candidate. Further research is necessary to determine the immune defense mechanisms modulated in shrimp larvae following probiotic administration. Microarrays with gene contents ranging from a few dozen to a few thousand genes have been generated in L. stylirostris. The use of this technology may prove to be a valuable tool to identify ways of improving the shrimp immune response.

\section{Acknowledgements}

The authors are indebted to Dr Elizabeth Ficko-Blean for the critical review of this manuscript and her help in editing the English language. This work was partly supported by a grant from the Overseas French Ministry, SEOM n ${ }^{\circ} 09 / 1217976 / \mathrm{BF}$ and 12/024079/D and by the DEDUCTION project funded by the Institut Français de Recherche pour l'Exploitation de la Mer, the Provincial Institutions (Province Sud, Province Nord et Province des Iles Loyautés) and by the Government of New Caledonia. 
Thanks are due to the zootechnical staff of the experimental hatchery of Saint-Vincent (F. Broutoi, S. Collet, S. Gerart, J.R. Mailliez, J.M. Peignon) for its help in supplying L. stylirostris larvae and postlarvae. The authors also thank M. Dupont-Rouzeyrol and R. Dufourcq (Institut Pasteur, New-Caledonia) for performing the initial agar-well-diffusion assays of the bacterial collection, T. Laugier for valuable comments on this article and the "Plate-forme de Recherche pour les Sciences du Vivant de Nouvelle-Calédonie (PFV-NC)" for allowing access to the qPCR facility. Any opinions, findings, and conclusions or recommendations expressed in this material are those of the authors and do not necessarily reflect the views of the supporting bodies mentioned herein.

\section{References}

Aguirre-Guzman, G., Vazquez-Juarez, R., Ascencio, F., 2001. Differences in the susceptibility of american white shrimp larval substages (Litopenaeus vannamei) to four Vibrio species. J. Invertebr. Pathol. 78(4), 215-219.

Bowman, J.P., 2007.Bioactive compound synthetic capacity and ecological significance of marine bacterial genus Pseudoalteromonas. Mar Drugs 5(4), 220-41.

Cabello, F.C., 2006 Heavy use of prophylactic antibiotics in aquaculture: a growing problem for human and animal health and for the environment. Environ. Microbiol. 8(7), 1137-44.

Castex, M., Lemaire, P., Wabete, N., Chim, L., 2010. Effect of probiotic Pediococcus acidilactici on antioxidant defences and oxidative stress of Litopenaeus stylirostris under Vibrio nigripulchritudo challenge. Fish Shellfish Immun. 28, 622-631.

Castillo, N.A., Perdigón, G., de Moreno de Leblanc, A., 2011. Oral administration of a probiotic Lactobacillus modulates cytokine production and TLR expression improving the 
immune response against Salmonella enterica serovar Typhimurium infection in mice. BMC Microbiol. 11:177, $12 \mathrm{pp}$.

Chalkiadakis, E., Dufourcq, R., Schmitt, S., Brandily, C., Kervarec, N., Coatanea, D., Amir, H., Loubersac, L., Chanteau, S., Guezennec, J., Dupont-Rouzeyrol, M., Simon-Colin, C., 2013. Partial characterization of an exopolysaccharide secreted by a marine bacterium, Vibrio neocaledonicus sp. nov.,from New Caledonia. J. Appl. Microbiol. 114, 1702-1712.

Chiu, C-H., Guu, Y-K., Liu, D-H., Pan, T-M., Cheng, W., 2007. Immune responses and gene expression in white shrimp Litopenaeus vannamei induced by Lactobacillus plantarum. Fish Shellfish Immun. 23, 364-377.

De Lorgeril, J., Gueguen, Y., Goarant,C., Goyard, E., Mugnier, C., Fievet, J., Piquemal, D., Bachère, E., 2008. A relationship between antimicrobial peptide gene expression and capacity of selected shrimp line to survive a Vibrio infection. Mol. Immunol. 45, 3438-3445.

Destoumieux, D., Munoz, M., Bulet, P., Bachère, E., 2000. Penaeidins, a family of antimicrobial peptides from penaeid shrimp (Crustacea, Decapoda).Cell Mol Life Sci. 57(89), 1260-1271.

Dheilly, A., Soum-Soutéra, E., Klein, G.L., Bazire, A., Compère, C., Haras, D., Dufour, A., 2010. Antibiofilm activity of the marine bacterium Pseudoalteromonas sp. strain 3J6. Appl. Environ. Microbiol. 76, 3452-3461.

Dunn, A.K., Millikan, D.S., Adin, D.M., Bose, J.L., Stabb, E.V., 2006. New rfp- and pES213derived tools for analyzing symbiotic Vibrio fischeri reveal patterns of infection and lux expression in situ. Appl Env Microbiol 72, 802-810.

Gauthier, G., Gauthier, M., Christen, R., 1995. Phylogenetic analysis of the genera Alteromonas, Shewanella and Moreitella using genes coding for the small-subunit RNA sequences and division of the genus Alteromonas into two genera, Alteromonas and 
Pseudoalteromonas gen. Nov., and proposal of twelve new species combinations. Int. J. Syst.

Bacteriol. 45, 755-761.

Goarant, C., Régnier, F., Brizard, R., Marteau, A.L., 1998. Acquisition of susceptibility to Vibrio Penaeicida in Penaeus stylirostris postlarvae and juveniles. Aquaculture 169, 291296.

Goarant, C., Merien, F., Berthe, F., Mermoud, I., Perolat, P., 1999. Arbitrarily primed PCR to type Vibrio spp. pathogenic for shrimp. Appl Environ Microbiol. 65(3), 1145-51.

Goarant, C., Ansquer, D., Herlin, J., Domalain, F., Imbert, F., de Decker, S., 2006. 'Summer syndrome' in Litopenaeus stylirostris in New Caledonia: pathology and epide- miology of the etiological agent, Vibrio nigripulchritudo. Aquaculture 253, 105-113.

Gomez-Gil, B., Roque, A., Turnbull, J.F., 2000. The use and selection of probiotic bacteria for use in the culture of larval aquatic organisms. Aquaculture 191, 259-270.

Goudenège, D., Labreuche, Y., Krin, E., Ansquer, D., Mangenot, S., Calteau, A., Médigue, C., Mazel, D., Polz, M.F., Le Roux, F., (2013). Comparative genomics of pathogenic lineages of Vibrio nigripulchritudo identifies virulence-associated traits. ISME J. 7(10), 1985-96.

Isnansetyo, A., Istiqomah, I., Muhtadi, Sinansari, S., Hernawan, R.K., Triyanto, Widada, J., (2009). A potential bacterial biocontrol agent, strain S2V2 against pathogenic marine Vibrio in aquaculture. World J. Microbiol. Biotechnol. 25, 1103-1113.

Kersarcodi-Watson, A., Kaspar, H., Lategan, M.J., Gibson, L., 2008. Probiotics in aquaculture: The need, principles ans mechanisms of action and screening processes. Aquaculture 274, 1-14.

Labreuche, Y., Veloso, A., de la Vega, E., Gross, P.S., Chapman, R.W., Browdy, C.L., Warr, G.W., 2009. Non-specific activation of antiviral immunity and induction of RNA interference 
may engage the same pathway in the Pacific white leg shrimp Litopenaeus vannamei. Dev. Comp. Immunol. 34 (11), 1209-1218.

Labreuche, Y., Pallandre, L., Ansquer, D., Herlin, J., Wapotro, B., Le Roux, F., 2012. Pathotyping of Vibrio isolates by multiplex PCR reveals a risk of virulent strain spreading in New Caledonian shrimp farms. Microb Ecol. 63(1), 127-38.

Lakshmi, B.,Viswanath, B., Sai Gopal, D. V. R., 2013. Probiotics as Antiviral Agents in Shrimp Aquaculture. Hindawi Publishing Corporation, Journal of Pathogens, Vol. 2013, Article ID 424123, 13 pp.

Le Roux, F., Labreuche, Y., Davis, B.M., Iqbal, N., Mangenot, S., Goarant , C., Mazel, D., Waldor, M.K., 2011. Virulence of an emerging pathogenic lineage of Vibrio nigripulchritudo is dependent on two plasmids. Environ. Microbiol. 13, 296-306.

Long, R.A., Azam, F., 2001. Antagonistic interactions among marine pelagic bacteria. Appl Environ Microbiol. 67, 4975-4983.

Maeda, M., Shibata, A., Biswas, G., Korenaga, H., Kono, T., Itami, T., Sakai, M., 2013. Isolation of lactic acid bacteria from kuruma shrimp (Marsupenaeus japonicus) intestine and assessment of immunomodulatory role of a selected strain as Probiotic. Mar Biotechnol. DOI 10.1007/s10126-013-9532-1.

Nimrat, S., Boonthai, T., Vuthiphandchai, V., 2011. Effects of probiotic forms, compositions of and mode of probiotic administration on rearing of Pacific white shrimp (Litopenaeus vannamei) larvae and postlarvae. Animal Feed Science and Technology 169 (3-4), 244-258.

Pfaffl, M.W., 2001. A new mathematical model for relative quantification in real-time RTPCR. Nucleic Acids Res.;29 (9):e 45. 
Pham, D., Charmantier; G., Wabete N., Boulo, V., Broutoi, F., Mailliez, J.-R., Peignon, J.-M., Charmantier-Daures, M., 2012. Salinity tolerance, ontogeny of osmoregulation and zootechnical improvement in the larval rearing of the Caledonian Blue Shrimp, Litopenaeus stylirostris (Decapoda, Penaeidae). Aquaculture 362-363, 10-17.

Sawabe, T., Kita-Tsukamoto, K. \& Thompson, F. L., 2007. Inferring the evolutionary history of vibrios by means of multilocus sequence analysis. J. Bacteriol. 189, 7932-7936.

Thompson, F.L., Iida, T., Swings, J., 2004. Biodiversity of Vibrios. Microbiol. Mol. Biol. Rev. 68 (3), 403-31.

Thompson, J., Gregory, S., Plummer, S., Shields, R.J., Rowley, A.F., 2010. An in vitro and in vivo assessment of the potential of Vibrio spp. as probiotics for the Pacific White shrimp, Litopenaeus vannamei. J. Appl. Microb. 109, 1177-1187.

Thuy, H.T.T., Nga, L.P., Loan, T.T.C., 2011. Antibiotic contaminants in coastal wetlands from Vietnamese shrimp farming. Environ. Sci. Pollut. Res. Int. 18, 835-841. doi: $10.1007 / \mathrm{s} 11356-011-0475-7$.

Travers, M.A., Barbou, A., Le Goïc, N., Huchette, S., Paillard, C., Koken, M. 2008 Construction of a stable GFP-tagged Vibrio harveyi strain for bacterial dynamics analysis of abalone infection. FEMS Microbiol Lett. 289(1), 34-40.

Verschuere, L., Rombaut, G., Sorgeloos, P., Verstraete, W., 2000. Probiotic Bacteria as Biological Control Agents in Aquaculture. Microbiol. Mol. Biol. Rev. 64 (4), 655-671.

Villegas, C. T., Kanazawa, A., 1980. Rearing of the larval stages of prawn, Penaeus japonicus BATE, using artificial diet. Memoirs of the Kagoshima University Research Center, South Pacific 1, 43-49. 
Walling, E., Vourey, E., Ansquer, D., Beliaeff, B., Goarant, C., 2010. Vibrio nigripulchritudo monitoring and strain dynamics in shrimp pond sediments. J. Appl. Microbiol. 108 (6), 20032011.

Wang, Y.C., Chang, P.S., Chen, H.Y., 2008. Differential time-series expression of immunerelated genes of pacific white shrimp Litopenaeus vannamei in response to dietary inclusion of beta-1,3-glucan. Fish Shellfish Immunol. 24(1), 113-21.

Wozniak R.A., Waldor M.K., 2010. Integrative and conjugative elements: mosaic mobile genetic elements enabling dynamic lateral gene flow. Nat. Rev. Microbiol. 8(8), 552-63.

Zokaeifar, H., Balcazar, J.L., Saad, C.R., Kamarudin, M.S., Sijam, K., Arshad, A., Nejat, N., 2012. Effects of Bacillus subtilis on the growth performance, digestive enzymes immune gene expression and disease resistance of white shrimp, Litopenaeus vannamei. Fish Shellfish Immun. 33, 115683-689. 


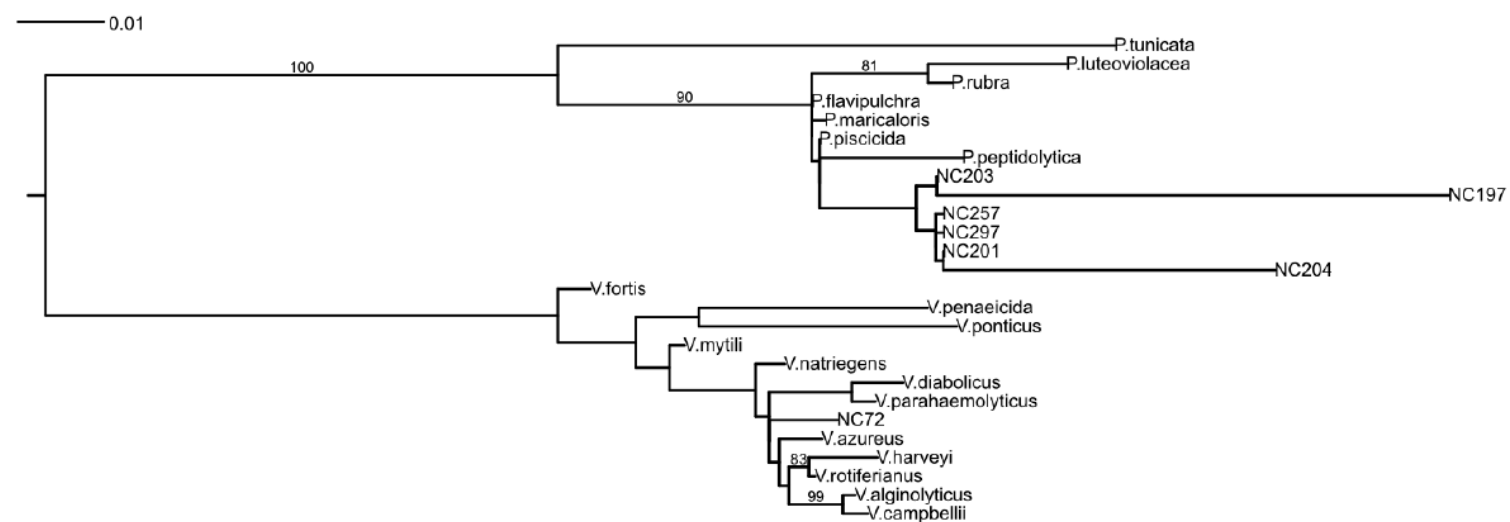

Figure 1 


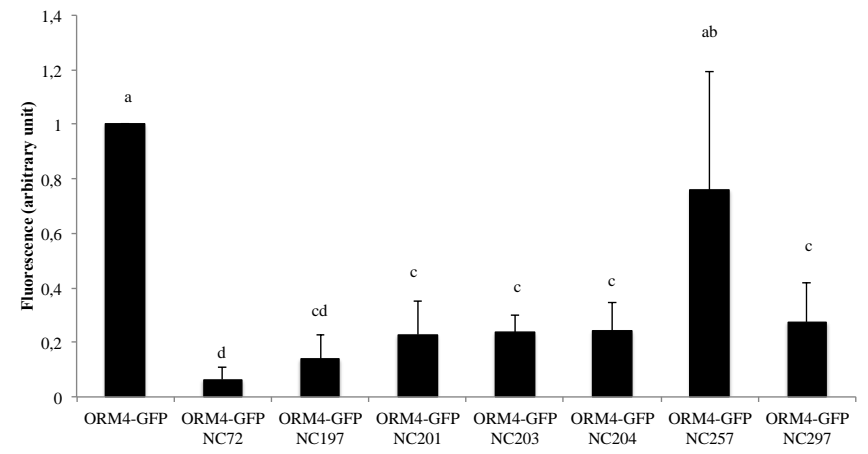

Figure 2 


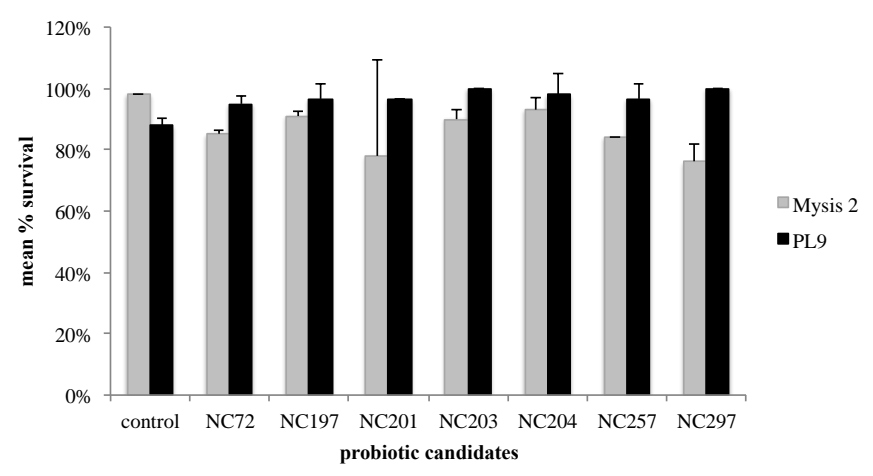

Figure 3 


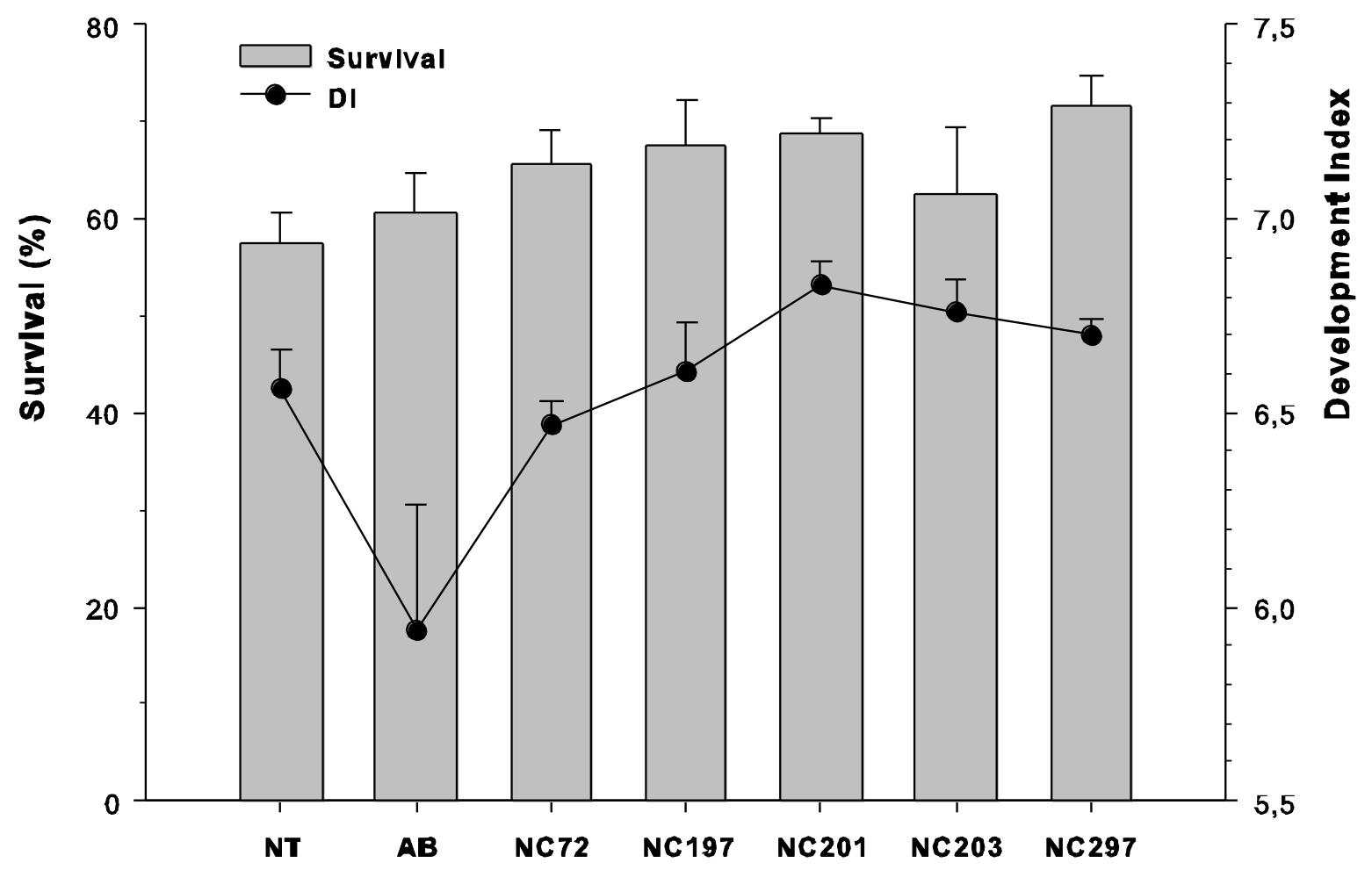

Figure 4 


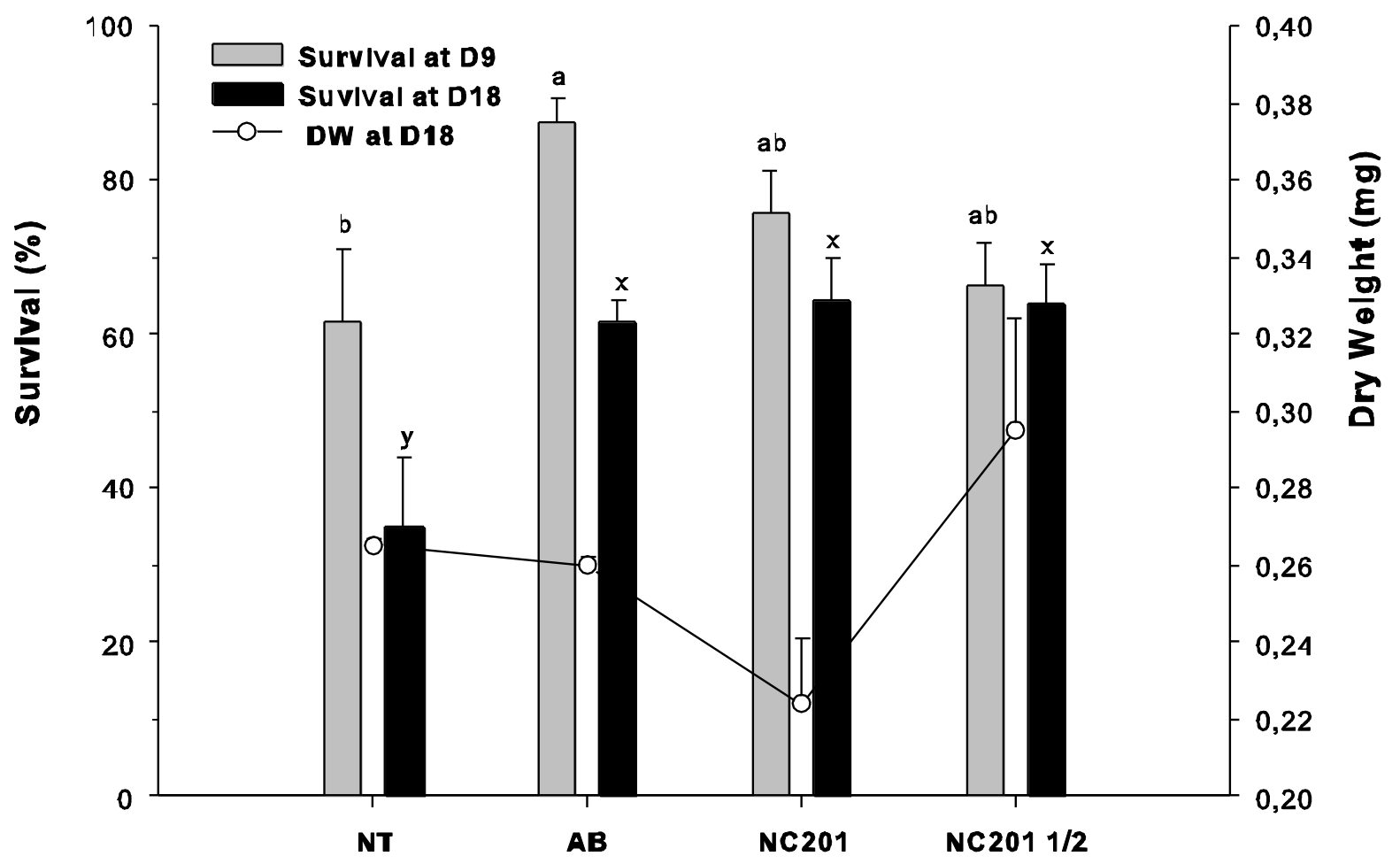

Figure 5 


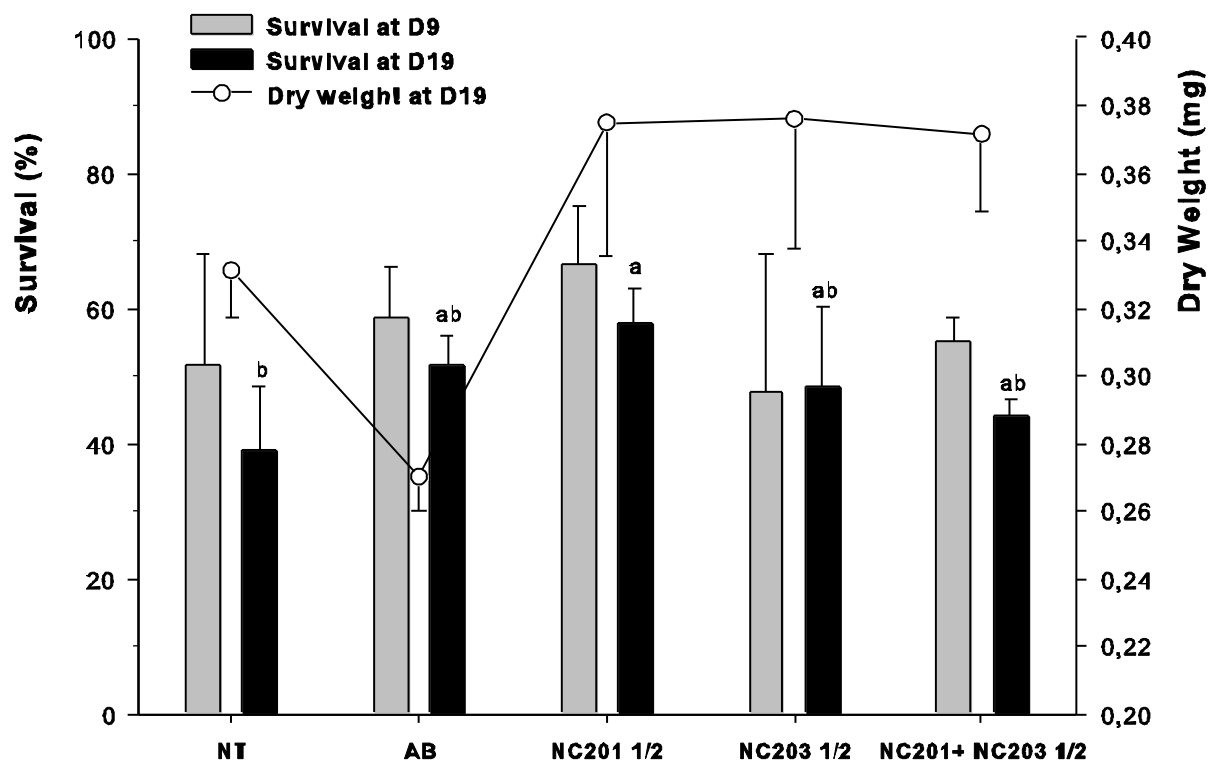

Figure 6 

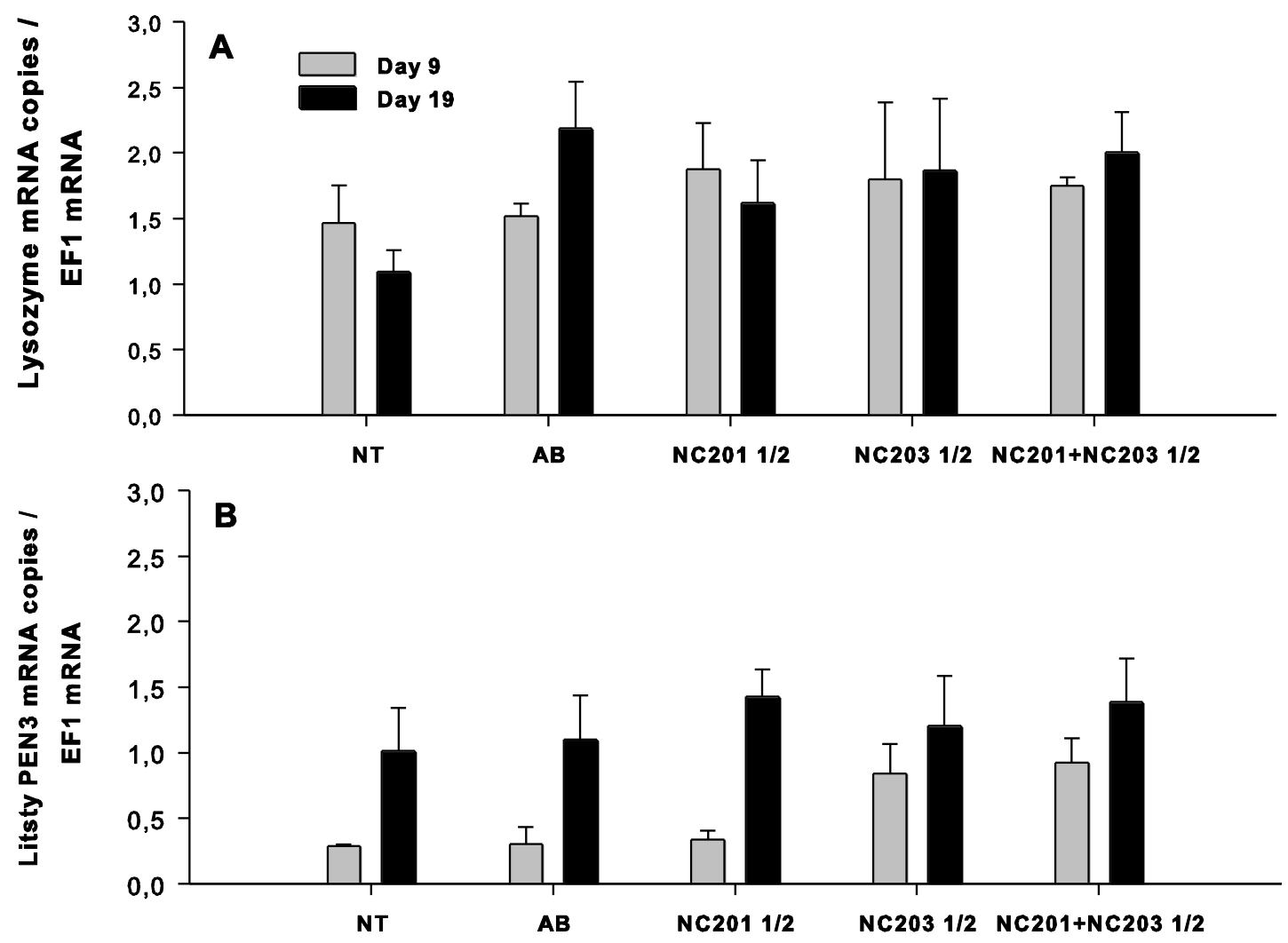

Figure 7 


\begin{tabular}{|c|c|c|c|c|c|c|c|}
\hline & NC 72 & NC197 & NC201 & NC203 & NC204 & NC257 & NC297 \\
\hline LDC & + & - & - & - & - & - & - \\
\hline ODC & + & - & - & - & - & - & - \\
\hline CIT & + & - & - & - & - & & - \\
\hline IND & + & - & - & - & - & & + \\
\hline GEL & + & + & + & + & + & + & + \\
\hline GLU & + & - & - & - & - & & - \\
\hline MAN & + & - & - & - & - & - & - \\
\hline SAC & + & - & - & - & - & - & - \\
\hline AMY & + & - & - & - & - & - & - \\
\hline OX & + & + & + & - & - & - & + \\
\hline N2 & + & + & + & + & + & + & + \\
\hline
\end{tabular}

Table 1: API20E gallery test results for 11 out of 23 reactions : (+) indicates positive reaction; (-) indicates negative reaction.

\begin{tabular}{|c|c|c|c|c|c|c|}
\hline & $\begin{array}{c}\text { NT } \\
\text { survival } \\
(\%) \\
\text { At D9 } \\
\end{array}$ & $\begin{array}{c}\text { NC201 } \\
\text { survival } \\
(\%) \\
\text { at D9 } \\
\end{array}$ & $\begin{array}{c}\text { NT } \\
\text { survival }(\%) \\
\text { at D19 }\end{array}$ & $\begin{array}{c}\text { NC201 } \\
\text { survival } \\
(\%) \\
\text { at D19 } \\
\end{array}$ & $\begin{array}{c}\text { NT } \\
\text { MDW (mg) } \\
\text { at D19 }\end{array}$ & $\begin{array}{c}\text { NC201 } \\
\text { MDW (mg) } \\
\text { at D19 }\end{array}$ \\
\hline 1rst comparison & 71.1 & 55.0 & 6.2 & 43.1 & 0.177 & 0.268 \\
\hline $2^{\text {nd }}$ comparison & 68.1 & 69.4 & 29.0 & 41.5 & 0.242 & 0.179 \\
\hline $3^{\text {rd }}$ comparison & 64.4 & 85.0 & 50.2 & 65.8 & 0.246 & 0.222 \\
\hline Mean value $( \pm$ SE) & $78.0( \pm 3.6)$ & $69.8( \pm 15.0)$ & $28.5( \pm 22.0)$ & $50.1( \pm 13.6)$ & $0.228( \pm 0.039)$ & $0.223( \pm 0.045)$ \\
\hline
\end{tabular}

Table 2 : Litopenaeus stylirostris survival rates at D9, D19 and dry weight at D19 in the fourth experiment at pilot scale in $1.5 \mathrm{~m}^{3}$ tanks. 
Figure 1: Phylogenetic tree based on the Maximum-Likelihood method, using partial 16S rRNA gene sequences. Bootstrap values are expressed as percentages of 100 replications; only values $>80 \%$ are shown. The tree is drawn to scale, with branch lengths in the same units as those of the evolutionary distances used to infer the phylogenetic tree. GenBank accession

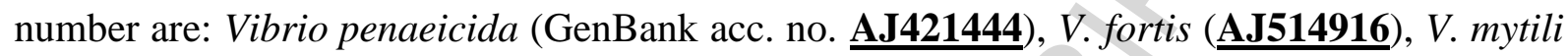

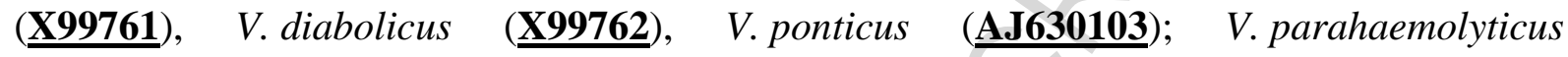

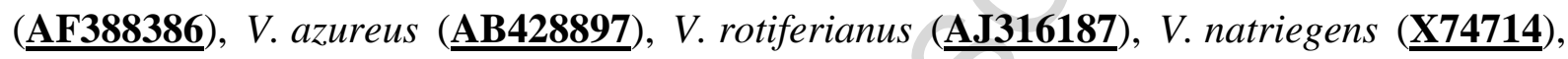

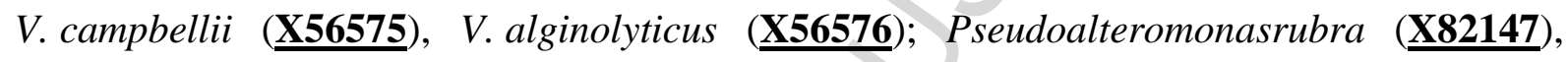

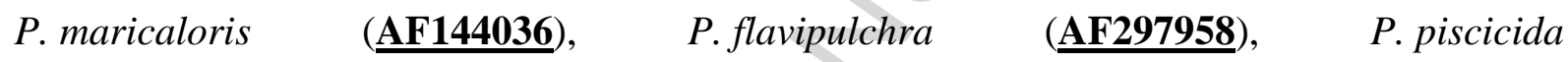

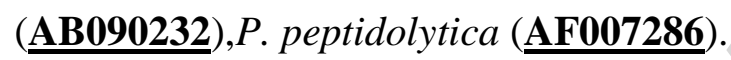

Figure 2: Antagonistic effect of probiotic candidates on $V$. harveyi growth determined after $48 \mathrm{~h}$ co-culture, using fluorescence expressed by $V$. harveyi ORM4-GFP as a proxy for its planktonic growth. The GFP-derivative V. harveyi and the probiotic candidate strains were co-cultured at equal starting concentrations $\left(1 \times 10^{5}\right.$ CFU.mL $\left.{ }^{-1}\right)$.

Figure 3 : Mysis 2 or PL9 shrimp larvae were exposed to a single dose of $1 \times 10^{5}$ CFU.mL ${ }^{-1}$ of the probiotic candidates to determine effects on survival. Shrimp survival expressed as Means \pm SD. Overall, no significant differences were observed (Kruskal-Wallis, P>0.05) between survival and the probiotic candidate strain used.

Figure 4 : Survival and development index in L. stylirostris larvae nine days after hatching and depending on the prophylactic treatment. NT : no treatment; AB: antibiotic; NC72, NC197, NC 201, NC203, and NC297 : 5 potential probionts.

Figure 5 : Survival at D9 and D18 and final dry weight in L. stylirostris larval rearing depending on the prophylactic treatment. NT : no treatment; AB: antibiotic; NC201 : isolate 
201 in daily administration; NC201 $1^{1 / 2}$ : isolate 201 delivered every two days. Bars sharing different letters are significantly different $(\mathrm{p}<0,05)$.

Figure 6 : Survival at D9 and D19 and final dry weight in L. stylirostris larval rearing depending on the prophylactic treatment. NT : no treatment; $\mathrm{AB}$ : antibiotic; NC201 ${ }^{1 / 2}$ : isolate 201 delivered every two days; $\mathrm{NC}_{203} 3^{1 / 2}$ : isolate 203 delivered every two days; NC201+ NC203 ${ }^{1 / 2}$ : mix of isolates 201 and 203 delivered every two days. Bars sharing different letters are significantly different $(\mathrm{p}<0,05)$.

Figure 7 : Gene transcripts level coding Lysozyme (A) and Listy PEN 3 (B) in L. stylirostris 9-days old and 19-days old animals according the prophylactic treatment. NT : no treatment; $\mathrm{AB}$ : antibiotic; $\mathrm{NC} 201^{1 / 2}$ : isolate 201 delivered every two days; $\mathrm{NC} 203^{1 / 2}$ : isolate 203 delivered every two days; NC201+ NC203 ${ }^{1 / 2}$ : mix of isolates 201 and 203 delivered every two days. 